\title{
Competition between Hydrogen and Halogen Bonds in Complexes of 6- OX-Fulvene with Pnicogen and Chalcogen Electron Donors
}

\author{
Mingchang Hou, ${ }^{a}$ Qingzhong Li, ,,a Steve Scheiner ${ }^{*, b}$
}

((Dedication, optiona

Quantum chemical calculations are applied to complexes of 6-OXfulvene $\left(\mathrm{X}=\mathrm{H}, \mathrm{Cl}, \mathrm{Br}\right.$, I) with $\mathrm{ZH}_{3} / \mathrm{H}_{2} \mathrm{Y}(\mathrm{Z}=\mathrm{N}, \mathrm{P}, \mathrm{As}, \mathrm{Sb} ; \mathrm{Y}=\mathrm{O}, \mathrm{S}, \mathrm{Se}$, $\mathrm{Te})$ to study the competition between the hydrogen bond and the halogen bond. The H-bond weakens as the base atom grows in size and the associated negative electrostatic potential on the Lewis base atom diminishes. The pattern for the halogen bonds is more complicated. In most cases, the halogen bond is stronger for the heavier halogen atom, and pnicogen electron donors are more

\section{Introduction}

Non-covalent interactions play an important role in supramolecular chemistry, ${ }^{[1]}$ molecular recognition, ${ }^{[2]}$ and material science, ${ }^{[3]}$ which has motivated researchers to find and understand novel types of non-covalent interactions. Hydrogen bonding $(\mathrm{HB})$ is one of the most important non-covalent interactions, and the most mature. ${ }^{[4-6]}$ The halogen bond (XB) represents another important interaction, with similar properties and applications to the $\mathrm{HB}$, and has received more and more attention in recent years. ${ }^{[7-12]}$ In general, non-covalent interactions can be thought of as Lewis acid-base interactions. In the study of halogen bonds, the concept of a " $\sigma$-hole" has been used to explain the formation of halogen bonds by Clark et al, ${ }^{[13]}$ and was later extended to other types of non-covalent interactions. The $\sigma$ hole can be interpreted as a positive molecular electrostatic potential (MEP) region centered along an extension of the R-X axis. XBs have been utilized in synthesis of organic conductive electrical materials, ${ }^{[14-16]}$ topological chemistry, ${ }^{[17]}$ and layer by layer assembly and chemical separation. ${ }^{[18,19]}$ The XB also plays a key role in biological molecules and as a potential tool in drug design. ${ }^{[20.21]}$

[a] Dr. M. Hou, Q. Li

Laboratory of Theoretical and Computational Chemistry and School of

Chemistry and Chemical Engineering, Yantai University

Yantai 264005(China)

Fax: (+86)535-6902063

E-mail: li70316@sohu.com

[b] Prof. S. Scheiner

Department of Chemistry and Biochemistry, Utah State University, Logan, UT 84322-0300 (USA)

E-mail: steve.scheiner@usu.com

Supporting information for this article is available on the WWW under http://www.chemphyschem.org or from the author.((Please delete if not appropriate)) strongly bound than chalcogen. Halogen bonds to chalcogen atoms strengthen in the $\mathrm{O}<\mathrm{S}<\mathrm{Se}<\mathrm{Te}$ order, whereas the pattern is murkier for the pnicogen donors. In terms of competition, most halogen bonds to pnicogen donors are stronger than their $\mathrm{H}$-bond analogues, but there is no clear pattern with respect to chalcogen donors. O prefers a H-bond, while halogen bonds are favored by Te. For $\mathrm{S}$ and $\mathrm{Se}$, I-bonds are strongest, followed $\mathrm{Br}, \mathrm{H}$, and $\mathrm{Cl}$-bonds in that order.

With the understanding of the formation, properties, nature, and applications of various non-covalent interactions, the competition, ${ }^{[22]}$ cooperation $^{[23]}$ and coexistence ${ }^{[24]}$ among various non-covalent bonds have generated extensive research. It is especially important to study the competition between hydrogen bonds and halogen bonds, as these two types of interactions are directional and relatively strong, and their importance in crystal engineering originates from their shared dependence upon longrange electrostatic forces] ${ }^{25-29}$ By combining interactions that do not compete for the same molecular binding sites it is, in principle possible to avoid or at least minimize "synthon cross-over"[30] thereby producing architectures of considerable complexity. ${ }^{[31-34]}$ Moreover, it is well known that hydrogen bonding plays an important role in the human body; for example, human DNA structure is highly dependent upon hydrogen bonds. Also, it has been demonstrated that the Holliday junction, which is an intermediate formed during homologous recombination of DNA, is stabilized through the $\mathrm{O} \cdots \mathrm{Br} \mathrm{XB}$ interaction, whereas the hydrogen-bonded isomer is not formed. ${ }^{[35]}$

There are many factors that can regulate the competition between $\mathrm{HB}$ and XB, e.g. solvent polarity. This competition can be influenced by choice of solvent (polarity) to direct the selfassembly of co-crystals. Formation of hydrogen-bonded cocrystals is favored in less polar solvents and halogen-bonded cocrystals by more polar solvents. ${ }^{[36]}$ Cooperativity also affects the competition between HB and XB. For example, the presence of magnesium bonding has a positive synergistic effect on the strength of $\mathrm{HB}$ and $\mathrm{XB}$, but the enhancing effect on both interactions is different. ${ }^{[37]}$ Of course, whether it is $\mathrm{HB}$ or $\mathrm{XB}$, its strength depends mainly on the properties of Lewis acid and Lewis base. Therefore, many studies have been conducted on the effects of Lewis acid and Lewis base on the competition between HB and XB. ${ }^{[38-41]}$ Herrebout et al. ${ }^{[38]}$ used infrared and Raman spectra to study the $\mathrm{HB}$ and $\mathrm{XB}$ complexes formed by 
trimethylamine (TMA), dimethyl ether (DME) and methyl fluoride (MF) with $\mathrm{CHF}_{2}$ I. They found that both $\mathrm{HB}$ and $\mathrm{XB}$ are present in the complexes $\mathrm{TMA}^{\mathrm{C}} \mathrm{CHF}_{2} \mathrm{I}$ and $\mathrm{DME} \cdots \mathrm{CHF}_{2} \mathrm{I}$, while only $\mathrm{XB}$ is present in the $\mathrm{MF} \cdots \mathrm{CHF}_{2}$ I complex. In another work by Herrebout, it was found that only $\mathrm{HB}$ exists in the $\mathrm{TMA}^{\cdots} \mathrm{CHF}_{2} \mathrm{Br}$ complex, indicating that the transition from $\mathrm{I}$ to $\mathrm{Br}$ greatly reduces the strength of the halogen bond. ${ }^{[39]}$ Although the competition for HB and $X B$ has attracted widespread attention, there remain a number of open questions. Moreover, most of the previous studies focused mainly on the competition between $\mathrm{HB}$ and $\mathrm{XB}$ formed by the same molecule. We turn our focus here to the competition between $\mathrm{HB}$ and $\mathrm{XB}$ within different molecules.

In this work, we chose 6-OX-fulvene $(X=\mathrm{H}, \mathrm{Cl}, \mathrm{Br}, \mathrm{I})$ as the Lewis acid and $\mathrm{ZH}_{3}(\mathrm{Z}=\mathrm{N}, \mathrm{P}, \mathrm{As}, \mathrm{Sb})$ and $\mathrm{H}_{2} \mathrm{Y}(\mathrm{Y}=\mathrm{O}, \mathrm{S}$, Se, Te) as the Lewis bases. Both molecules can be bonded by a HB or XB when $X$ is a hydrogen atom or a halogen atom. Fulvene is not only a precursor for the synthesis of natural compounds, ${ }^{[2,43]}$ but also a starting material for the synthesis of novel substituted titanium-based biometallic organic anticancer drugs. ${ }^{[4]}$ Therefore, fulvene has an important potential application in medicine and biology. Structurally, being an isomer of benzene, it is a conjugated system having an extracyclic double bond. Although fulvene is non-aromatic, it can be converted into an aromatic structure by substitution at the 6-position, and its aromaticity has also attracted widespread attention. ${ }^{[45]}$ Therefore, we chose fulvene derivatives to participate in the formation of $H B$ and $X B$. We selected hydrides of $\mathrm{V}$ and $\mathrm{VI}$ group atoms as Lewis bases to study the effects of different Lewis bases on the strength of hydrogen bonds and halogen bonds. Through this study, we hope to generate a better understanding of the nature of $\mathrm{HB}$ and $\mathrm{XB}$ and the influence of Lewis acid and Lewis base on the strength of both interactions.

\section{Computational Methods}

All calculations were performed using the Gaussian 09 program. ${ }^{[46]}$ Geometries were optimized at the MP2 computational level with the aug-cc-pVDZ basis set for all atoms except I, Sb, and Te atoms, for which the aug-cc-pVDZ-PP basis set, with its relativistic corrections, was adopted. Frequency calculations at the same level confirmed that the structures obtained correspond to energetic minima. The interaction energy was calculated by the supermolecular method involving the energies of the monomers at the geometries they adopt within the complex. This quantity was corrected for the basis set superposition error (BSSE) by the counterpoise protocol proposed by Boys and Bernardi. ${ }^{[4]}$ Using the nature bond orbital (NBO) method ${ }^{[48]}$ within the Gaussian 09 program, charge transfer and second-order perturbation energy were obtained. The AIM2000 package ${ }^{[49]}$ was used to assess the topological parameters at each bond critical point (BCP) including electron density, its Laplacian, and energy density. Molecular electrostatic potentials (MEPs), and their extrema, were calculated on the $0.001 \mathrm{au}$ isodensity surface at the MP2/aug-ccpVDZ level using the WFA-SAS program. ${ }^{[50]}$

\section{Results and Discussion}

\subsection{Geometries and Energetics of Complexes}

Figure 1 illustrates the MEPs of 6-OX-fulvene and two types of Lewis bases $\left(\mathrm{ZH}_{3}\right.$ and $\left.\mathrm{H}_{2} \mathrm{Y}\right)$. A red region of positive MEP occurs along the extension of the $\mathrm{OH} / \mathrm{OX}$ bond in $6-\mathrm{OH}$-fulvene and its halogenated derivatives. The intensity of this so-called $\sigma$-hole rises in the $\mathrm{OCl}<\mathrm{OBr}<\mathrm{OI}<\mathrm{OH}$ sequence. Regarding the various Lewis bases, a blue or green area of negative MEP is observed in the lone pair area of the $\mathrm{Z} / \mathrm{Y}$ atom of $\mathrm{ZH}_{3}$ and $\mathrm{YH}_{2}$. The magnitude of the minimum is largest for first-row atoms $\mathrm{N}$ and $\mathrm{O}$, then drops for succeeding rows of the periodic table. It is more negative for chalcogen than pnicogen atoms, with the exception of $\mathrm{NH}_{3} / \mathrm{OH}_{2}$ where it is the pnicogen atom that has a slightly more negative minimum.

\section{Lewis base}

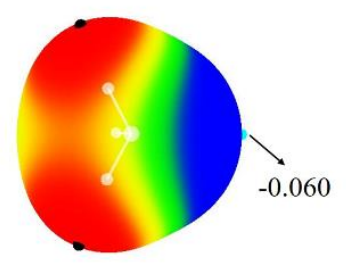

$\mathrm{NH}_{3}$

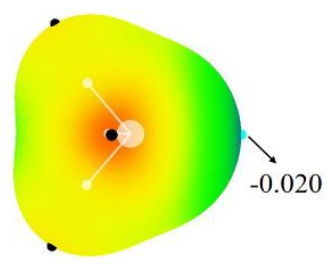

$\mathrm{AsH}_{3}$

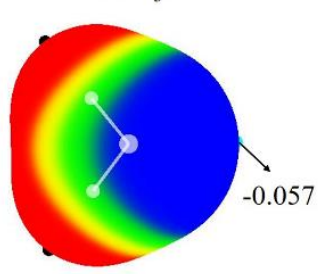

$\mathrm{H}_{2} \mathrm{O}$

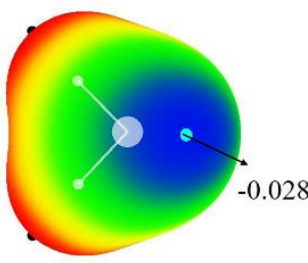

$\mathrm{H}_{2} \mathrm{Se}$

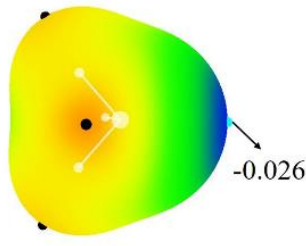

$\mathrm{PH}_{3}$

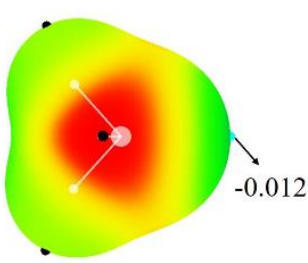

$\mathrm{SbH}_{3}$

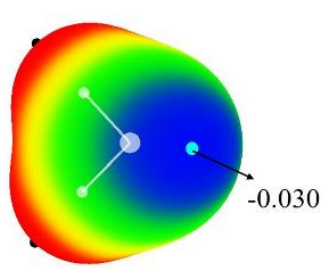

$\mathrm{H}_{2} \mathrm{~S}$

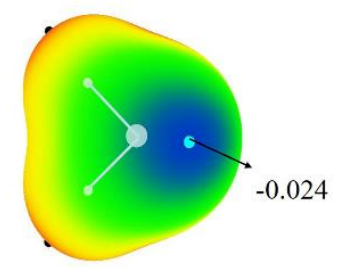

$\mathrm{H}_{2} \mathrm{Te}$

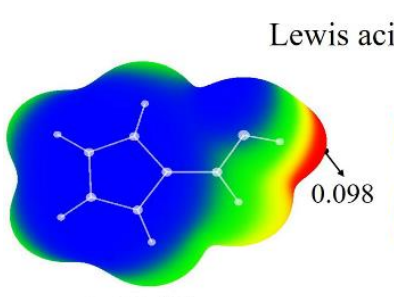

6-OH-fulvene

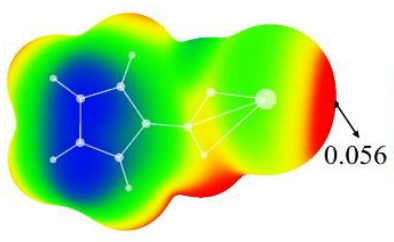

6-OBr-fulvene

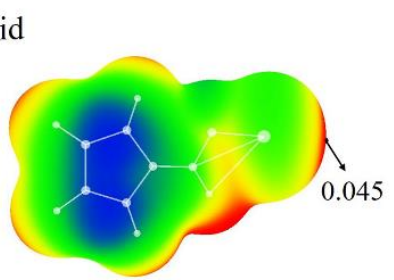

6-OCl-fulvene

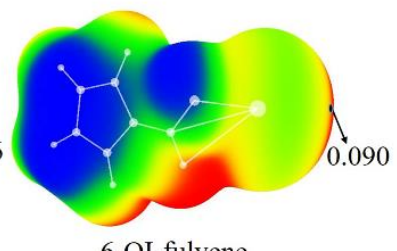

6-OI-fulvene
Figure 1 MEP diagrams of the Lewis acids and bases. Color ranges, in a.u., are: red, greater than 0.020; yellow, between 0.020 and 0 ; green, between 0 and -0.020 ; blue, less than -0.020 . Arrows refer to values of maxima and minima 

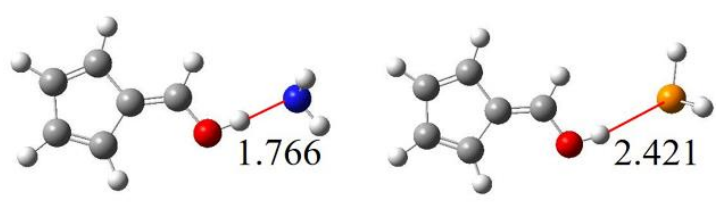

$\mathrm{H}-\mathrm{N}$
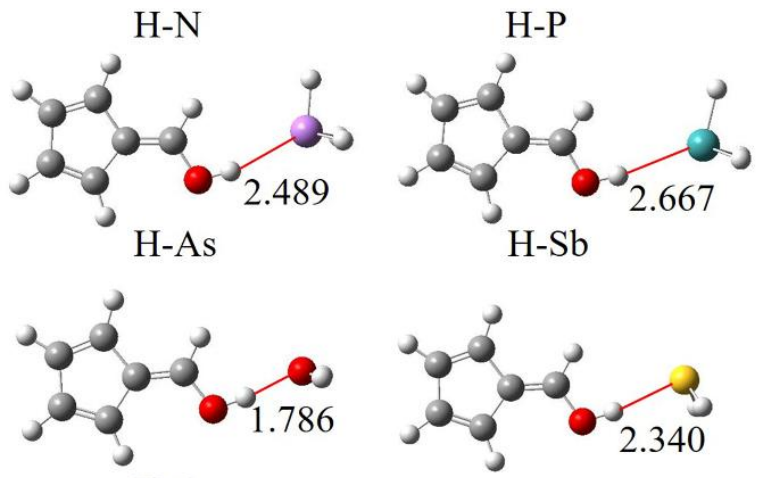

$\mathrm{H}-\mathrm{O}$

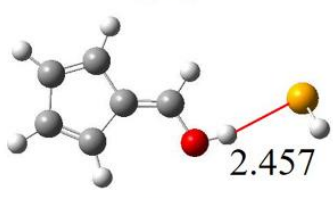

$\mathrm{H}-\mathrm{Se}$

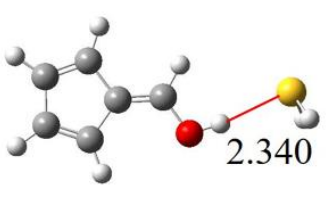

$\mathrm{H}-\mathrm{S}$

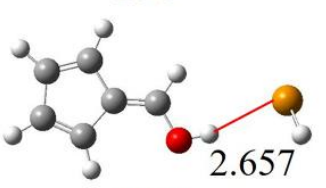

$\mathrm{H}-\mathrm{Te}$

Figure 2 The optimized structures of the HB complexes and distances are in $\AA$

The optimized structures of the HB complexes shown in Figure 2 display the anticipated nearly linear $\mathrm{OH} \cdots \mathrm{Y} / \mathrm{Z}$ arrangement, which is essentially duplicated for the $X B$ dimers that are illustrated in Figure $S 1$. The notation for each complex shows first the $\mathrm{H}$ or $\mathrm{X}$ atom on the fulvene, followed by the $\mathrm{Y} / \mathrm{Z}$ atom of the base with which it is interacting. There are only very minor inconsistencies from one structure to the next. For example, one of the $\mathrm{H}$ atoms of $\mathrm{NH}_{3}$ lies opposite the $\mathrm{C}$ to which the $\mathrm{OH}$ is connected in $\mathrm{H}-\mathrm{N}$ whereas it is more of a cis orientation for the other pnicogen atoms. There is also a diminishing $\mathrm{OH} \cdots \mathrm{Y}$ linearity as the $\mathrm{Y}$ atom grows in size. The $\mathrm{H} / \mathrm{X} \cdots \mathrm{Y} / \mathrm{Z}$ intermolecular distance is shortest for the $\mathrm{H}$-bonded systems, consistent with the small size of the bridging $\mathrm{H}$. This distance elongates along with the size of the acceptor $Y / Z$ atom. With regard to the $\mathrm{H}$-bonds, this length is slightly greater for the pnicogen than for the chalcogen atoms, with the exception of $\mathrm{NH}_{3} \mathrm{vs} \mathrm{OH}_{2}$. It is the bonds to the chalcogen acceptors that are longer in the cases of the XBs. In general, all of these bonds elongate as the acceptor atom grows in size although there are one or two exceptions. For example, $\mathrm{R}(\mathrm{Cl} \cdots \mathrm{Te})$ distance is quite a bit shorter than $\mathrm{R}(\mathrm{Cl} \cdots \mathrm{Se})$.

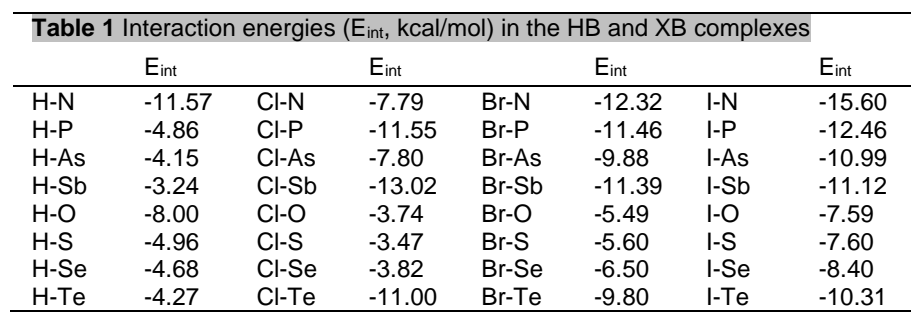

The interaction energies $\left(E_{\text {int }}\right)$ of the various complexes displayed in Table 1 cover the broad range between 3 and 16 $\mathrm{kcal} / \mathrm{mol}$. The HB quantities are largest for first-row $\mathrm{N}$ and $\mathrm{O}$ acceptors, with the others much smaller, diminishing slowly as the acceptor atom grows larger. The XB dimers obey rather different trends, not necessarily consistent from one $X$ atom to the next. For example, the strongest $\mathrm{Cl}$-bonds are formed by the

heaviest $\mathrm{Sb}$ and Te acceptor atoms, and the pnicogen complexes are consistently stronger than their chalcogen counterparts. For the case of the I-bonds, it is the lightest $\mathrm{N}$ pnicogen that forms the strongest bond, but the heaviest chalcogen for which this is true.

Within the context of the HB systems, $E_{\text {int }}$ rises steadily along with the Lewis base $V_{\min }$. Their linear relationship is displayed in Figure S2 with correlation coefficients of 0.985 and 0.999 for the $\mathrm{ZH}_{3}$ and $\mathrm{H}_{2} \mathrm{Y}$ bases, respectively. This close correlation is consistent with the notion that electrostatics provide a guiding factor in these HB complexes.
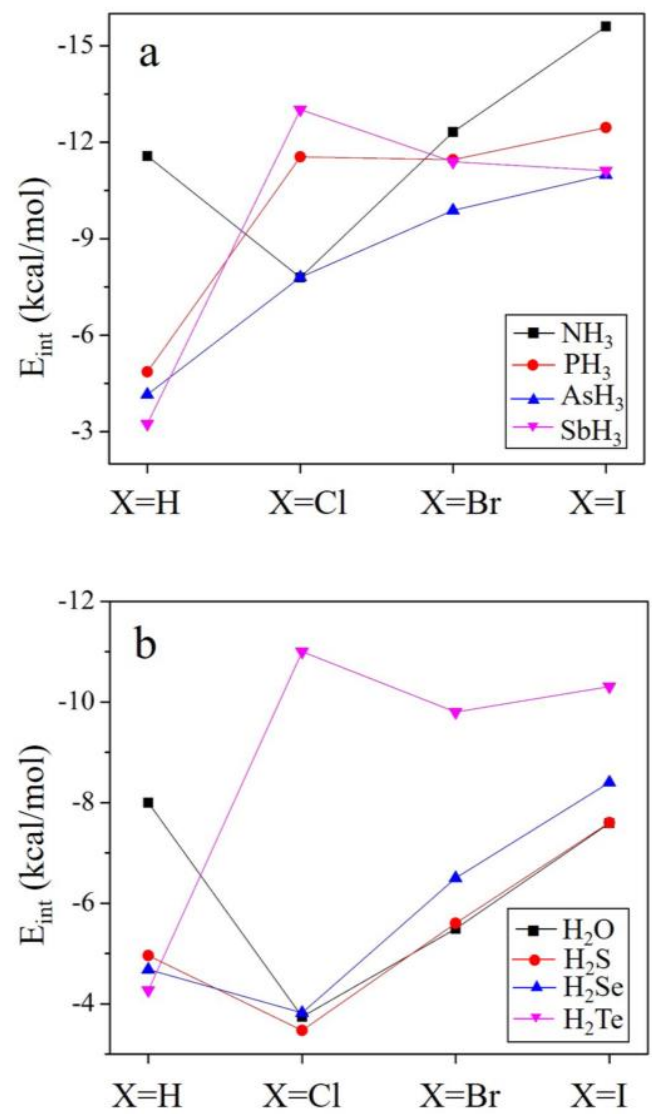

Figure 3 The plot of the interaction energy $\left(\mathrm{E}_{\text {int }}\right)$ with the change of $\mathrm{X}$ atom in complexes with a) $\mathrm{ZH}_{3}$ and $\mathrm{b}$ ) $\mathrm{H}_{2} \mathrm{Y}$.

The sometimes erratic patterns within the larger picture of these energetics may perhaps be best understood visually through the graphic presentation of Figure 3 . Beginning with the pnicogen bonds in Figure 3a, the interaction energy for $\mathrm{AsH}_{3}$ rises steadily from $\mathrm{H}$ to $\mathrm{Cl}$, and then to $\mathrm{Br}$ and I. However, the other $\mathrm{ZH}_{3}$ molecules do not behave this simply. In the cases of $\mathrm{PH}_{3}$ and $\mathrm{SbH}_{3}$, the $\mathrm{H}$-bond is also the weakest, but there is disagreement as to which halogen bond is strongest. It is the $\mathrm{Cl}$-bond that is strongest for $\mathrm{SbH}_{3}$, but the I-bond for $\mathrm{PH}_{3}$. There is a clear $\mathrm{Cl}<\mathrm{Br}$ $<$ I order for $\mathrm{NH}_{3}$, but its $\mathrm{H}$-bond is stronger than $\mathrm{Cl}$, and is by far the strongest of the $\mathrm{H}$-bonds considered here. The latter behavior of the $\mathrm{H}$-bond repeats itself for the chalcogen electron donors in Figure $3 \mathrm{~b}$, with first-row $\mathrm{H}_{2} \mathrm{O}$ replacing $\mathrm{NH}_{3}$. All of the chalcogen donors, with the exception of $\mathrm{TeH}_{2}$, follow a strengthening halogen bond order of $\mathrm{Cl}<\mathrm{Br}<\mathrm{I}$, whereas $\mathrm{TeH}_{2}$ finds the $\mathrm{Cl}$ bond stronger than any other. Given the different orders for $\mathrm{H}, \mathrm{Cl}$, $\mathrm{Br}$, and I-bonds, the interaction energies are clearly dependent upon factors other than simply the magnitude of $V_{\min }$ on the base.

It is known that chlorine is a mediocre halogen donor in most cases, when compared to its heavier congeners. However, when 6-OCl-fulvene binds with $\mathrm{SbH}_{3}$ and $\mathrm{H}_{2} \mathrm{Te}$, they form a strong halogen bond. In a previous study, it was found that $\mathrm{HBe}$ and $\mathrm{H}_{2} \mathrm{~B}$ 
radicals bind very strongly with $\mathrm{CIF}$, resulting in $\mathrm{Cl}$ transfer from $\mathrm{CIF}$ to the radical. ${ }^{[51]}$ For the given $\mathrm{Br}$ donor, the $\mathrm{XB}$ interaction energy is more negative in the sequence $\mathrm{AsH}_{3}<\mathrm{SbH}_{3} \approx \mathrm{PH}_{3}<$ $\mathrm{NH}_{3}$, while the energetics pattern is the reverse of that of $\mathrm{V}_{\mathrm{s}, \mathrm{min}}$ on $\mathrm{H}_{2} \mathrm{Y}$. A similar reverse change is also found for the IB complexes with $\mathrm{YH}_{2}$.

Turning next to a comparison between $\mathrm{HB}$ and $\mathrm{XB}$ interactions, XBs win the competition for $\mathrm{ZH}_{3}$ other than $\mathrm{NH}_{3}$, for which the $\mathrm{HB}$ is comparable to the $\mathrm{Br}$-bond. Within the subset of $\mathrm{YH}_{2}$ bases, the $\mathrm{XBs}$ are considerably stronger for $\mathrm{TeH}_{2}$, and $\mathrm{HB}$ is the clear winner for $\mathrm{OH}_{2}$. For $\mathrm{SH}_{2}$ and $\mathrm{SeH}_{2}$, the $\mathrm{HB}$ is stronger than the $\mathrm{CIB}$ but weaker than both $\mathrm{BrB}$ and IB.

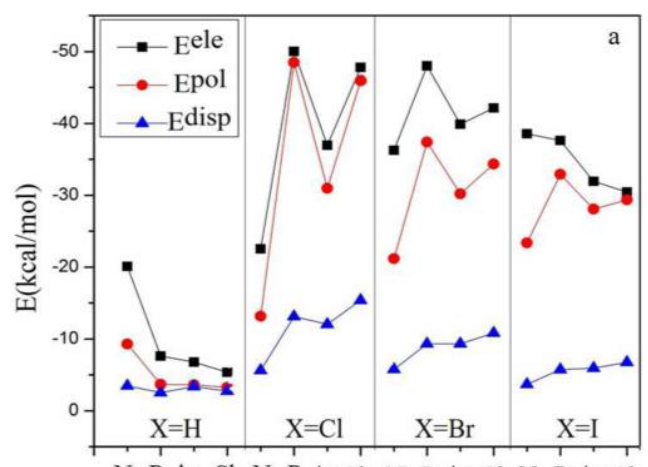

N P As Sb N P As Sb N P As Sb N P As Sb

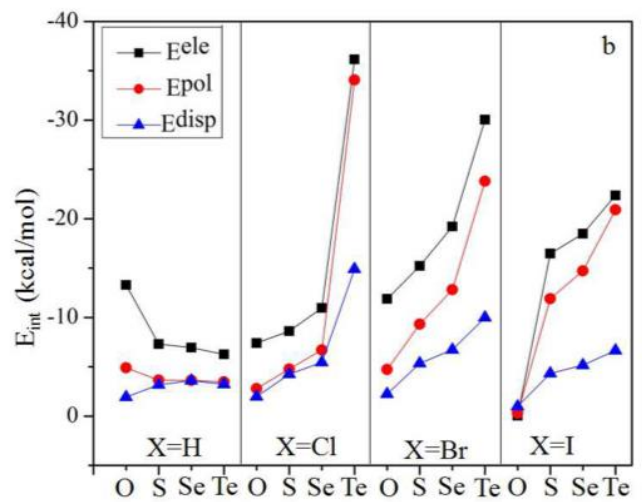

Figure 4 Electrostatic ( $\left.E^{\mathrm{ele}}\right)$, polarization $\left(E^{\mathrm{pol}}\right)$ and dispersion ( $\left.E^{\text {disp }}\right)$ energies in complexes with a) $\mathrm{ZH}_{3}$ and b) $\mathrm{H}_{2} \mathrm{Y}$.

\subsection{Analysis of Wave Function}

Partitioning of the total interaction energy into its constituent parts opens a window into the nature of the interaction. The interaction energies of $\mathrm{HB}$ and $\mathrm{XB}$ systems are decomposed here into five terms: electrostatic energy $\left(E^{\mathrm{ele}}\right)$, exchange energy $\left(E^{\mathrm{ex}}\right)$, repulsion energy $\left(E^{\mathrm{rep}}\right)$, polarization energy $\left(E^{\mathrm{pol}}\right)$ and dispersion energy $\left(E^{\text {disp }}\right)$. The three attractive terms $\left(E^{\mathrm{ele}}, E^{\mathrm{pol}}\right.$, and $\left.E^{\text {disp }}\right)$ are presented in Figure 4 for each of the complexes. In the HB interaction, $E^{\mathrm{ele}}$ is larger than $E^{\mathrm{pol}}$ and $E^{\text {disp }}$, indicating electrostatic interaction dominates the HB interaction, consistent with the parallel between $E_{\text {int }}$ and $V_{\text {min }}$ of the base. For the $\mathrm{HB}$ interaction with $\mathrm{NH}_{3}$ and $\mathrm{H}_{2} \mathrm{O}$, $E^{\text {pol }}$ is more negative than $E^{\text {disp }}$, while both terms are almost equal for the other $\mathrm{ZH}_{3}$ and $\mathrm{H}_{2} \mathrm{Y}$. Clearly, the relative contribution of each term is related to the strength of the Lewis base. While decreasing the minimum MEP on the electron donor atom, $E^{\mathrm{ele}}$ also drops, as is also the case for $E^{\mathrm{ool}}$. For the $\mathrm{XB}$ interactions, the electrostatic term is the largest but by only a narrow margin. In the bonds with $\mathrm{YH}_{2}$, all three attractive terms grow as the Lewis base heavy atom becomes larger, but the pattern is less clear for $\mathrm{ZH}_{3}$, where there appears to be a minimum for $\mathrm{AsH}_{3}$.

Table 2 Electron density $(\rho)$, Laplacian $\left(\nabla^{2} \rho\right)$, and total energy density $(H)$ at the intermolecular BCP in the HB and XB complexes, all in au

\begin{tabular}{llllllll} 
& $\rho$ & $\nabla^{2} \rho$ & $H$ & & $\rho$ & $\nabla^{2} \rho$ & $H$ \\
\hline H-N & 0.045 & 0.121 & -0.002 & Br-N & 0.050 & 0.123 & -0.005 \\
H-P & 0.020 & 0.039 & 0.001 & Br-P & 0.057 & 0.064 & -0.012 \\
H-As & 0.019 & 0.035 & -0.001 & Br-As & 0.049 & 0.060 & -0.009 \\
H-Sb & 0.016 & 0.031 & -0.001 & Br-Sb & 0.048 & 0.044 & -0.009 \\
H-O & 0.032 & 0.141 & 0.005 & Br-O & 0.025 & 0.085 & 0.001 \\
H-S & 0.020 & 0.054 & 0.002 & Br-S & 0.027 & 0.068 & 0.001 \\
H-Se & 0.019 & 0.045 & 0.001 & Br-Se & 0.031 & 0.064 & -0.001 \\
H-Te & 0.017 & 0.033 & 0.001 & Br-Te & 0.038 & 0.056 & -0.004 \\
Cl-N & 0.040 & 0.121 & 0.001 & I-N & 0.047 & 0.108 & -0.006 \\
Cl-P & 0.070 & 0.061 & -0.018 & I-P & 0.046 & 0.063 & -0.008 \\
Cl-As & 0.053 & 0.069 & -0.009 & I-As & 0.041 & 0.055 & -0.006 \\
Cl-Sb & 0.057 & 0.041 & -0.013 & I-Sb & 0.038 & 0.040 & -0.006 \\
Cl-O & 0.020 & 0.076 & 0.002 & I-O & 0.025 & 0.089 & 0.000 \\
Cl-S & 0.019 & 0.059 & 0.002 & I-S & 0.025 & 0.063 & -0.000 \\
Cl-Se & 0.023 & 0.059 & 0.001 & I-Se & 0.027 & 0.058 & -0.001 \\
Cl-Te & 0.051 & 0.059 & -0.009 & I-Te & 0.030 & 0.048 & -0.003 \\
\hline
\end{tabular}

Another means of scrutinizing the interactions arises from an AIM analysis of the topology of the electron density. There is a bonding path leading from $\mathrm{H} / \mathrm{X}$ to $\mathrm{Y} / \mathrm{Z}$ in each complex, confirming the existence of a noncovalent bond. The most important properties of each bond critical point are reported in Table 2 where $\rho$ refers to the density, $\nabla 2 \rho$ to its Laplacian, and $H$ is the energy density. The electron density ranges from 0.016 to 0.057 $\mathrm{au}$, which lies in the range suggested for noncovalent interactions ${ }^{[52]}$ For the $\mathrm{H}$-bonds, both $\rho$ and $\nabla 2 \rho$ decay as the $\mathrm{Y} / \mathrm{Z}$ atom grows larger. The XBs obey a different patterns however. The Laplacian of the density is consistently largest for the smallest $Y / Z$ atom, generally duplicating the HB trends. But the density behaves more erratically. $\rho_{\mathrm{BCP}}$ peaks for chalcogen atoms for fourth-row Te. But in the context of pnicogen electron donors, there is a predilection for $\mathrm{P}$ over the other atoms. $\mathrm{H}$ is quite small for most of these complexes, and of variable sign.

With respect to the particular flavor of halogen bond, neither $\rho$ nor its Laplacian obeys a simple and clear pattern as one compares $\mathrm{Cl}$ with $\mathrm{Br}$ and $\mathrm{I}$. As is commonly observed, an exponential relationship is present between the electron density at the bond critical point and the binding distance for the HB interactions, as may be seen in Figure S3. However, there is no such relationship for the XB interactions, in keeping with some of the erratic patterns mentioned above.

Table 3 Charge transfer (CT, e) from Lewis acid to base molecule, and secondorder perturbation energies $\left(\mathrm{E}^{2}, \mathrm{kcal} / \mathrm{mol}\right)$ for transfer from $\mathrm{Y} / \mathrm{Z}$ lone pair to $\mathrm{O}$ $\mathrm{H} / \mathrm{O}-\mathrm{X} \sigma^{*}$ antibonding orbital in the $\mathrm{HB}$ and $\mathrm{XB}$ complexes

\begin{tabular}{llllll}
\hline & $\mathrm{CT}$ & $\mathrm{E}^{2}$ & & $\mathrm{CT}$ & $\mathrm{E}^{2}$ \\
\hline $\mathrm{H}-\mathrm{N}$ & 0.056 & 39.16 & $\mathrm{Br}-\mathrm{N}$ & 0.123 & 50.38 \\
$\mathrm{H}-\mathrm{P}$ & 0.032 & 16.01 & $\mathrm{Br}-\mathrm{P}$ & 0.272 & 88.07 \\
$\mathrm{H}-\mathrm{As}$ & 0.030 & 14.11 & $\mathrm{Br}-\mathrm{As}$ & 0.239 & 66.69 \\
$\mathrm{H}-\mathrm{Sb}$ & 0.030 & 12.66 & $\mathrm{Br}-\mathrm{Sb}$ & 0.302 & 74.92 \\
$\mathrm{H}-\mathrm{O}$ & 0.026 & 21.24 & $\mathrm{Br}-\mathrm{O}$ & 0.027 & 12.59 \\
$\mathrm{H}-\mathrm{S}$ & 0.033 & 16.84 & $\mathrm{Br}-\mathrm{S}$ & 0.082 & 25.76 \\
$\mathrm{H}-\mathrm{Se}$ & 0.036 & 16.09 & $\mathrm{Br}-\mathrm{Se}$ & 0.119 & 35.46 \\
$\mathrm{H}-\mathrm{Te}$ & 0.037 & 15.02 & $\mathrm{Br}-\mathrm{Te}$ & 0.232 & 66.99 \\
$\mathrm{Cl}-\mathrm{N}$ & 0.078 & 28.60 & $\mathrm{I}-\mathrm{N}$ & 0.126 & 54.28 \\
$\mathrm{Cl}-\mathrm{P}$ & 0.347 & 106.01 & $\mathrm{I}-\mathrm{P}$ & 0.227 & 78.29 \\
$\mathrm{Cl}-\mathrm{As}$ & 0.246 & 61.84 & $\mathrm{I}-\mathrm{As}$ & 0.209 & 63.12 \\
$\mathrm{Cl}-\mathrm{Sb}$ & 0.412 & 93.53 & $\mathrm{I}-\mathrm{Sb}$ & 0.245 & 63.94 \\
$\mathrm{Cl}-\mathrm{O}$ & 0.016 & 6.82 & $\mathrm{I}-\mathrm{O}$ & 0.039 & 19.22 \\
$\mathrm{Cl}-\mathrm{S}$ & 0.040 & 11.93 & $\mathrm{I}-\mathrm{S}$ & 0.102 & 33.87 \\
$\mathrm{Cl}-\mathrm{Se}$ & 0.061 & 16.64 & $\mathrm{I}-\mathrm{Se}$ & 0.133 & 41.20 \\
$\mathrm{Cl}-\mathrm{Te}$ & 0.329 & 99.37 & $\mathrm{I}-\mathrm{Te}$ & 0.200 & 58.77 \\
\hline
\end{tabular}

Focus may be placed on charge transfer effects through an NBO analysis of the wave functions. The total charge transfer from Lewis acid to base molecule is reported in Table 3 as CT. This quantity displays some interesting patterns. First with regard to $\mathrm{HBs}, \mathrm{CT}$ is largest for first-row $\mathrm{N}$ of the pnicogen donors, but smallest for first-row $\mathrm{O}$. In the case of the $\mathrm{XBs}$, there is a general 
tendency for larger charge transfer to the heavier electron donor atom: CT is more substantial for pnicogen than for chalcogen donors. This quantity is smaller for HBs than for XBs.

With respect to particular molecular orbitals, formation of any of these bonds is typically accompanied by transfer from the donor lone pair to the $\sigma^{*}$ antibonding $\mathrm{OH}$ or OX orbital. The energetic consequence of this transfer is measured as a secondorder perturbation energy $E^{2}$ in the NBO formalism. These quantities in Table 3 only partially mirror the total intermolecular charge transfer CT. Both indicate that $P$ is an anomalously strong electron donor, but only in halogen bonds. There is no such bump in these quantities for $S$ as the second-row neighbor of $P$. Indeed, the chalcogen donors display an almost uniform increase in the charge transfer parameters as the $Y$ atom grows in size. The same is true for the pnicogen donors, with the aforementioned anomaly for $\mathrm{P}$. And like $\mathrm{CT}, \mathrm{E}^{2}$ tends to be larger for pnicogen than for chalcogen donors. Like the total intermolecular CT, $E^{2}$ tends toward larger values for heavier $\mathrm{Y} / \mathrm{Z}$ atoms, but this pattern is not universal, and a number of exceptions are present in Table 3.

\subsection{Comparison with Previous Studies}

Given some unexpected patterns in the data presented here, it would be worthwhile to compare our results with previous work in this arena. Our results first confirm the tight relationship between the strength of the $\mathrm{H}$-bond and the basicity of the electron donor There is a widely recognized increasing halogen bond strength in the $\mathrm{Cl}<\mathrm{Br}<$ I sequence. While this trend is generally true here as well, anomalously strong $\mathrm{Cl}$-bonds occur for the fourth-row atoms in the $\mathrm{SbH}_{3}$ and $\mathrm{H}_{2} \mathrm{Te}$ bases. There is some precedent for this apparent oddity. For example, the $\mathrm{Cl}$-bond formed by $\mathrm{ClF}_{5}$ with $\mathrm{NH}_{3}$ is quite a bit stronger than the equivalent $\mathrm{XBs}$ formed by the $\mathrm{Br}$ and $\mathrm{I}$ analogues [53] Huber et al had earlier observed unexpected trends in the strengths of halogen-bond dimers of $\mathrm{CX}_{3}{ }^{\left[{ }^{54]}\right.}$ wherein the $\mathrm{XB}$ strength ran counter to electronegativity of the substituent and to the intensity of the $\sigma$-hole. The authors ascribed this pattern to charge transfer/polarization which opposes simple Coulombic considerations. A similar explanation may be invoked here in that the $\mathrm{CT}$ and $\mathrm{E}^{2}$ displayed in Table 3 for the $\mathrm{Cl}$-bonds involving $\mathrm{SbH}_{3}$ and $\mathrm{H}_{2} \mathrm{Te}$ are surprisingly large.

With respect to the electron donors, the HB pattern closely fits the MEP minima in Figure 1. HB strengths diminish as the $Y$ or $Z$ atom moves down in the periodic table column. $\mathrm{NH}_{3}$ forms a stronger $\mathrm{HB}$ than does $\mathrm{H}_{2} \mathrm{O}$, but it is the chalcogen that is a superior base for the second, third, and fourth row atoms, consistent with the Figure 1 data. But for the XBs, it is the pnicogen base which is uniformly stronger than its chalcogen counterpart in the same row of the periodic table, the reverse of the MEP trend. Again, this change in pattern can be traced to the charge transfer components in Table 3 where the pnicogen offers a stronger charge donor than does the chalcogen, with the exception of the first-row $\mathrm{N}$ and $\mathrm{O}$ atoms.

McDowell and Buckingham ${ }^{[55]}$ considered the capacity of CIF to engage in a $\mathrm{Cl}$-bond with bases similar to those examined here, but limited the latter to third-row atoms. Their interaction energies were consistently larger for $\mathrm{ZH}_{3}$ than for $\mathrm{YH}_{2}$, and by a sizable amount. As they progressed down either column of the periodic table, they observed a minimum interaction energy for secondrow $S$ and $P$ atoms, counter to conventional wisdom. However, these trends change, and become less regular, upon replacement of $\mathrm{H}$ atoms on the base by methyl groups. For example, whereas the $\mathrm{CIB}$ to the chalcogen base rises regularly $\mathrm{O}<\mathrm{S}<\mathrm{Se}$, the pattern for the pnicogen leads to the largest interaction energy for the second-row $P$.

Taking under consideration some of the irregular patterns noted here, in conjunction with certain anomalies noted by others in related systems, it would seem that the halogen bond is perhaps more complicated in its fundamental origin than is the hydrogen bond which obeys simpler rules. Further study is needed to fully unravel some of these issues, which reside in the properties of both the Lewis acid and base.

\section{Conclusions}

The HBs formed by $6-\mathrm{OH}$-fulvene are generally weaker than its XBs. Halogen bonds to pnicogen $\mathrm{ZH}_{3}$ molecules are stronger than those involving chalcogen $\mathrm{YH}_{2}$ units. The $\mathrm{XB}$ strength grows along with the size of the halogen atom, but the dependence upon donor atom size is less clear. The fourth-row Te atom offers the strongest XBs to chalcogen donors, whereas it is the smallest $\mathrm{N}$ pnicogen atom that provides the strongest $\mathrm{XB}$ (with an exception for the $\mathrm{Cl} \cdots \mathrm{Sb}$ bond which is surprisingly strong). The largest contributor to most of these bonds is the electrostatic attraction, but polarization energy does not lag far behind. Neither the total interaction energy, nor its electrostatic component, is strictly proportional to the value of the minimum in the electrostatic potential surrounding the electron donor molecule. Of the various binary complexes considered here, the

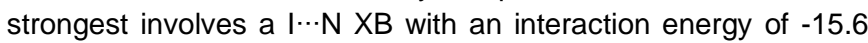
$\mathrm{kcal} / \mathrm{mol}$. The weakest interaction occurs in the HB to a pnicogen Sb atom.

\section{Acknowledgements}

This work was supported by the National Natural Science Foundation of China (21573188).

Keywords: Charge transfer, Molecular electrostatic potential, NBO, AIM, Energy decomposition

[1] a) C. B. Aakerçy, M. Baldrighi, J. Desper, P. Metrangolo, G. Resnati, Chem. Eur. J. 2013, 19, 16240-16247; b) R. W. Troff, T. Mäkelä, F. Topić, A. Valkonen, K. Raatikainen, K. Rissanen, Eur. J. Org. Chem. 2013, 1617-1637.

[2] S. Scheiner, Hydrogen Bonding: A Theoretical Perspective; Oxford University Press, New York, 1997.

[3] R.F.W. Bader, Atoms in molecules: A quantum theory; Oxford University Press, Oxford. 1990.

[4] G. A. Jeffrey, An Introduction to Hydrogen Bonding; Oxford University Press, New York, 1997.

[5] S. Scheiner, Noncovalent Forces; Spinger, 2015

[6] G. R. Desiraju, T. Steiner. The Weak Hydrogen Bond; Oxford University Press, Oxford, U.K., 1999.

[7] L. C. Gilday, T. Lang, A. Caballero, P. J. Costa, V. Felix, P. D. Beer. Angew. Chem. Int. Ed. 2013, 52, 4356-4360.

[8] A. V. Jentzsch, S. Matile, J. Am. Chem. Soc. 2013, 135, 5302-5303.

[9] H. R. Khavasi, A. A. Tehrani, Inorg. Chem. 2013, 52, 2891-2905.

[10] J. E. Ormond-Prout, P. Smart, L. Brammer, Cryst. Growth. Des. 2012, 12, 205-216.

[11] H. S. El-Sheshtawy, B. S. Bassil, K. I. Assaf, U. Kortz, W. M. Nau, J. Am. Chem. Soc. 2012, 134, 19935-19941.

[12] L. Meazza, J. A. Foster, K. Fucke, P. Metrangolo, G. Resnati, J. W. Steed Nat. Chem. 2013, 5, 42-47.

[13] T. Clark, M. Hennemann, J. S. Murray, P. Politzer, J. Mol. Model. 2007, 13, 291-296.

[14] B. Domercq, T. Devic, M. Fourmigué, P. Auban-Senzier, E. Canadell, J. Mater. Chem. 2001, 11, 1570-1575. 
[15] H. M. Yamamoto, Y. Kosaka, R. Maeda, J. Yamaura, A. Nakao, T. Nakamura, R. Kato, ACS. Nano. 2008, 2, 143-55.

[16] H. M. Yamamoto, J. Yamaura, R. Kato, J. Am. Chem. Soc. 1998, 120 5905-5913.

[17] A. Matsumoto, T. Tanaka, T. Tsubouchi, K. Tashiro, S. Saragai, S. Nakamoto, J. Am. Chem. Soc. 2002, 124, 8891-902.

[18] A. Farina, S. V. Meille, T. M. Messina, P. Metrangolo, G. Resnati, G. Vecchio, Angew. Chem. Int. Ed. 1999, 38, 2433-2436.

[19] F. Wang, N. Ma, Q. Chen, W. Wang, L. Wang, Langmuir. 2007, 23, 9540 9542.

[20] P. Auffinger, F. A. Hays, E. Westhof, P. S. Ho, Proc. Natl. Acad. Sci. U.S.A. 2004, 101, 16789-16794.

[21] A. R. Voth, H. P. Shing, Cur. Top. Med. Chem. 2007, 7, 1336-1348.

[22] a) T. Di. Paolo, C. Sandorfly, Can. J. Chem. 1974, 52, 3612 -3622; b) R. Massuda, C. Sandorfy, Can. J. Chem. 1977, 55, 3211-3217; c) J. Lieffrig O. Jeannin, T. Guizouarn, P. Auban-Senzier, M. Fourmigué, Cryst. Growth. Des. 2012, 12, 4248-4257.

[23] H. Duan, W. Zhang, J. Zhao, D. Liang, X. Yang, S. Jin, J. Mol. Model. 2012, 18, 3867-3875.

[24] C. B. Aakerçy, J. Desper, B. A. Helfrich, P. Metrangolo, T. Pilati, G. Resnati, A. Stevenazzi, Chem. Commun. 2007, 41, 4236-4238.

[25] C. B. Aakerőy, T. K. Wijethunga, J. Desper and M. Đaković, Cryst. Growth. Des. 2016, 16, 2662-2670.

[26] T. Clark, Faraday. Discuss. 2017, 203, 9-27.

[27] M. D. Perera, J. Desper, A. S. Sinha, C. B. Aakerőy, CrystEngComm, 2016, 18, 8631-8636.

[28] R. K. Rowe, P. S. Ho, Acta. Crystallogr. Sect. B: Struct. Sci. Cryst. Eng. Mater. 2017, 73, 255-264.

[29] C. A. Gunawardana, J. Desper, A. S. Sinha, M. Đaković, C. B. Aakeröy, Faraday Discuss. 2017, 203, 371-388.

[30] C. B. Aakerőy, P. D. Chopade, J. Desper, Cryst. Growth. Des. 2011, 11, 5333-5336.

[31] H. R. Khavasi, A. A. Tehrani, CrystEngComm, 2013, 15, 5813-5820.

[32] D. A. Adsmond, A. S. Sinha, U. B. R. Khandavilli, A. R. Maguire, S. E. Lawrence, Cryst. Growth. Des. 2016, 16, 59-69.

[33] T. Shirman, M. Boterashvili, M. Orbach, D. Freeman, L. J. W. Shimon, M. Lahav, M. E. van der Boom, Cryst. Growth. Des. 2015, 15, 4756-4759.

[34] H. R. Khavasi, M. Esmaeili, CrystEngComm, 2014, 16, 8479-8485.

[35] P. Metrangolo, G. Resnati, Science. 2008, 321, 918-919.

[36] C. C. Robertson, J. S. Wright, E. J. Carrington, R. N. Perutz, C. A. Hunter, L. Brammer, Chem. Sci. 2017, 8, 5392-5398.

[37] H. L. Xu, Q. Z. Li, S. Scheiner, ChemPhysChem, 2018, 19, 1456-1464

[38] N. Nagels, Y. Geboes, B. Pinter, F. D. Proft, W. A. Herrebout, Chemistry, 2014, 20, 8433-8443.

[39] Y. Geboes, F. D. Proft, W. A. Herrebout, J. Mol. Struct, 2018. 1165, 349355

[40] X. L. An, H. Y. Zhuo, Y. Y. Wang Y, Q. Z. Li, J. Mol. Model. 2013, 19, 4529-4535.

[41] X. L. An, X. Yang, B. Xiao, J. B. Cheng, Q. Z. Li, Mol. Phys. 2017, 115, 1614-1623.

[42] K. J. Stone, R. D. Little, Cheminform. 1984, 15, 1849-1853.

[43] A. J. Peloquin, R. L. Stone, S. E. Avila, J. Org. Chem. 2012, 77, 63716376.

[44] K. Strohfeldt, M. Tacke, Chem. Soc. Rev. 2008, 37, 1174-1187.

[45] S. Noorizadeh, E. Shakerzadeh, Comput. Theor. Chem. 2011, 964, 141 147.

[46] M. J. Frisch, G. W. Trucks, H. B. Schlegel, G. E. Scuseria,M. A. Robb, J. R. Cheeseman, G. Scalmani, V. Barone, B. Mennucci, G. A. Petersson H. Nakatsuji, M. Caricato,X. Li, H. P. Hratchian, A. F. Izmaylov, J. Bloino, G. Zheng, J. L. Sonnenberg, M. Hada, M. Ehara, K. Toyota, R. Fukuda, J. Hasegawa, M. Ishida, T. Nakajima, Y. Honda, O. Kitao, H. Nakai, T. Vreven, J. J. A. Montgomery, J. E. Peralta, F. Ogliaro, M. Bearpark, J. J Heyd, E. Brothers, K. N. Kudin, V. N. Staroverov, R. Kobayashi, J. Normand, K. Raghavachari, A. Rendell, J. C. Burant, S. S. lyengar, J. Tomasi, M. Cossi, N. Rega, J. M. Millam, M. Klene, J. E. Knox, J. B. Cross, V. Bakken, C. Adamo, J. Jaramillo, R. Gomperts, R. E. Stratmann O. A. Yazyev, J. Austin, R. Cammi, C. Pomelli, J. W. Ochterski, R. L. Martin, K. Morokuma, V. G. Zakrzewski, G. A. Voth, P. Salvador, J. J. Dannenberg, S. A. Dapprich, D. Daniels, O. Farkas, J. B. Foresman, J. V. Ortiz, J. Cioslowski, D. J. Fox, Gaussian 09, Revision A.02, Gaussian, Inc. Wallingford, CT, 2009

[47] S. F. Boys, F. Bernardi, Mol. Phys. 1970, 19, 553-556.
[48] A. E. Reed, L. A. Curtiss, F. Weinhold, Chem. Rev. 1988, 88, 899-926.

[49] R. F. W. Bader, AIM2000 Program, v. 2.0, McMaster University, Hamilton, Canada, 2000

[50] F. A. Bulat, A. Toro-Labbe, T. Brinck, J. S. Murray, P. Politzer, J. Mol. Model. 2010, 16, 1679-169

[51] Q.Z. Li, R. Li, S.C. Yi, W.Z. Li, J.B. Cheng. Struct. Chem. 2012. 23, 411416.

[52] P. Lipkowski, S.J. Grabowski, T. L. Robinson, J. Leszczynski, J. Phys. Chem. A 2004, 108, 10865-10872.

[53] S. Scheiner, J. Lu, Chem. Eur. J. 2018, 24, 8167-8177.

[54] S. M. Huber, E. Jimenez-Izal, J. M. Ugalde, I. Infante, Chem. Commun. 2012, 48, 7708-7710.

[55] S. A. C. McDowell, A. D. Buckingham, ChemPhysChem. 2018, 19, 1756 1765. 


\section{Entry for the Table of Contents}

\section{ARTICLES}

The complexes of 6-OX-fulvene $(\mathrm{X}=\mathrm{H}, \mathrm{Cl}, \mathrm{Br}, \mathrm{I})$ with $\mathrm{ZH}_{3} / \mathrm{H}_{2} \mathrm{Y}(\mathrm{Z}=\mathrm{N}$, $\mathrm{P}, \mathrm{As}, \mathrm{Sb} ; \mathrm{Y}=\mathrm{O}, \mathrm{S}, \mathrm{Se}, \mathrm{Te}$ ) have been used to study the competition between the hydrogen bond and the halogen bond. Most halogen bonds to pnicogen donors are stronger than their $\mathrm{H}$-bond analogues, but there is no clear pattern with respect to chalcogen donors.

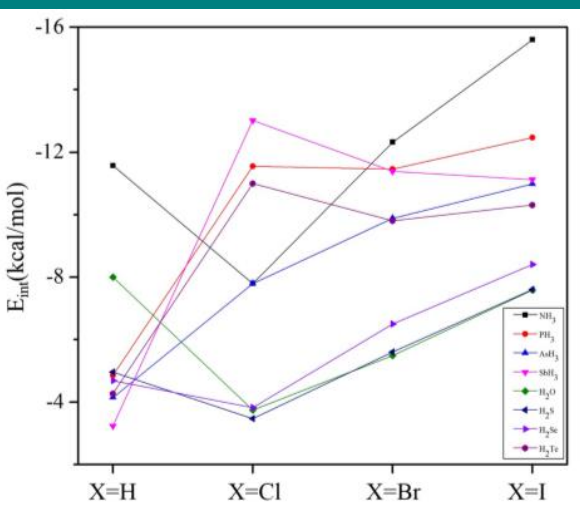

Mingchang Hou, Qingzhong Li, * Steve Scheiner*

Page No. - Page No.

Competition between Hydrogen and Halogen Bonds in Complexes of 6-OX-Fulvene with Pnicogen and Chalcogen Electron Donors 